Bulletin UASVM Food Science and Technology 70(2)/2013, 108-113

ISSN-L 2344-2344; Print ISSN 2344-2344; Electronic ISSN 2344-5300

\title{
New Trend on Halva Production: Dietetic Halva and Nougat. Production Technology and Compositions
}

\section{Emil RACOLŢA, Vlad MUREŞAN, Livia ŢICREA}

\author{
Faculty of Food Science and Technology, University of Agricultural Sciences and Veterinary Medicine \\ Cluj-Napoca, Romania, 3-5 Calea Mănăştur, 400372, Cluj-Napoca, Romania \\ emil.racolta@usamvcluj.ro
}

\begin{abstract}
In the last years sugar free confectionery market had grown steadily. These types of products are primarily addressed to diabetics and dieters, but the main driving factor of their growth is the increase of the obese population who raised concern about their health. Halva is known as a high caloric product with its nutritional energy higher than $500 \mathrm{kcal} / 100 \mathrm{~g}$, the demand of a sugar free version for this confectionery products group being those a current need. This work aimed to develop new products dietetic halva and nougat, their production technology and compositions being in detail described. A new trend on halva production was established by developing a dietetic halva and nougat. The problem which is solved by the current work is to assure a proper technology in order to obtain a dietetic halva similar in taste and texture with the conventional one.
\end{abstract}

Keywords: Dietetic halva, Dietetic nougat, Isomalt, Maltitol

\section{INTRODUCTION}

Nowadays, obesity and overweight are serious public health problems. In the European Union, based on the latest available data, more than half (52\%) of the adult population are now overweight or obese. Moreover, on average, 17\% of the adult population is obese (OECD, 2012). Across European Union, the prevalence of obesity - which presents greater health risks than overweight - ranges from $8 \%$ (Romania and Switzerland) to over 25\% (Hungary, United Kingdom) (Eurostat, 2011).

Consumers start to understand the message and functions of low calorie product categories which serve their demands for "healthy eating" when thinking about less calories and kind-to-the-teeth functions. Consequently, the demand for low calorie increases worldwide.

Halva is an old confectionery product which derives its hard texture from a mixture of cooked sugar syrup beat with soapwort (Saponaria officinalis) root extract - nougat, and sesame or sunflower paste - tahini (Eissa and Zohair, 2006). Sunflower halva, popular in countries from Eastern Europe is made of sunflower seeds tahini, instead of sesame (Mureşan et al., 2010). As Halva has a nutritional energy higher than $500 \mathrm{kcal} / 100 \mathrm{~g}$, the demand of a sugar free version for this confectionery products group becomes a current need.

This work aimed to develop new confectionery products - dietetic halva and nougat. The first objective was the elaboration of a new sugar free nougat technology with similar properties as the conventional one. The second objective of this work consisted on the development of a dietetic halva by replacing the conventional nougat with the sugar free one elaborated previously. 


\section{MATERIALS AND METHODS}

Materials

Sunflower seeds were an industrial mix from the 2012 harvest.

Isomalt was purchased from KUK (Germany). Isomalt tastes like sugar being an odorless, white, crystalline substance produced from sucrose. Firstly, sucrose is transformed into the reducing disaccharide named isomaltulose (Fig.1), by an enzymatic conversion with the aid of Protaminobacter rubrum. Then, isomaltulose is hydrogenated with hydrogen and a metal catalyst, resulting isomalt (Fig. 2) - a mixture of the isomers 1-O- $\alpha$-D-glucopyranosyl- D-mannitol dihydrate (1,1-GPM) and 6-O- $\alpha$-D-glucopyranosyl-D-sorbitol (1,6-GPS). The safety of isomalt was evaluated by the Joint Expert Committee on Food Additives of the WHO/FAO, deciding an acceptable daily intake of "not specified" (McNutt and Sentko, 2003).

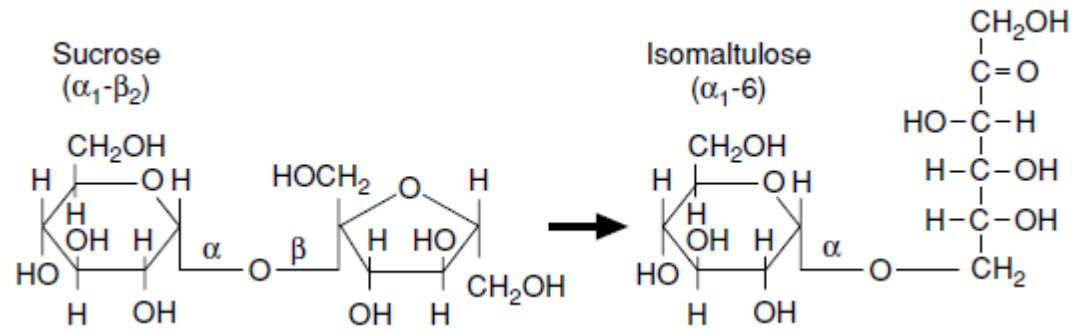

Fig. 1. Production of isomaltose by enzymatic transglucosidation (McNutt and Sentko, 2003)

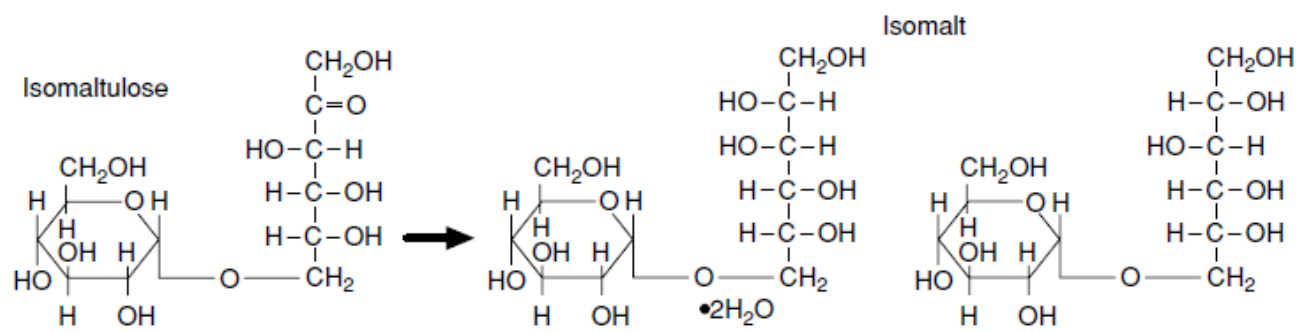

Fig. 2. Production of isomalt by hydrogenation (McNutt and Sentko, 2003)

Isomalt technological properties are:

- low hygroscopic - absorbs virtually no moisture at a temperature of $25^{\circ} \mathrm{C}$ and up to relative humidity of $85 \%$. All other polyols and sugar have higher hygroscopicity than isomalt. As a result, it is assumed that using isomalt will cause a more dry and stable halva when stored;

- is easier to process than sugar, while it is highly resistant to acids and enzymatic hydrolysis;

- has an acceptable solubility - $24 \mathrm{~g}$ in $100 \mathrm{~g}$ of solution at $24^{\circ} \mathrm{C}$, increasing at greater temperatures;

- has a high heat resistance (melting between 145 and $150^{\circ} \mathrm{C}$ ) - as its chemical structure is not altered at normal cooking temperatures, it is thought that will be a suitable ingredient for the dietetic nougat production (with operations of boiling and beating at high temperatures)

The nutritional advantages of using isomalt include: its low energy value $\sim 2.4 \mathrm{kcal} / \mathrm{g}$ (under the EC Nutrition and Labeling Directive) as compared to sucrose ( 4 kcal/g); does not significantly increase blood glucose or insulin levels; it works as a dietetic fiber; does not promote dental caries (McNutt and Sentko, 2003).

The maltitol syrup was purchased from Cargill (Maltidex ${ }^{\mathrm{TM}} 16311$ maltitol syrup, 76\%). Maltitol (Fig. 3) is obtained through enzymatic hydrolysis and liquefaction of grain-derived 
products having a high proportion of natural disaccharides (e.g. corn starch), then a catalytic hydrogenation of maltose, followed by filtration, purification and concentration in function of the final product (maltitol syrup dry matter, maltitol crystals). It possess a clean, pleasant natural sweetness, dissolves readily in water up to $165 \mathrm{~g} / 100 \mathrm{ml}$ at $25^{\circ} \mathrm{C}$, and has only $\sim 60 \%$ of the calories of sugar. Similar to other polyols it does not promote dental caries, and because it is digested through a slow enzymatic hydrolysis process it has a low glycemic index. According to Livesey (2003) low digestible carbohydrates, such as polyols (matitol and isomalt is included) pass into the large intestine where are a welcome food for gut flora (bacteria), which further produce short chain fatty acids that are beneficial to gut acidity and digestive functions, and have been shown to improve health in the colonic epithelium.

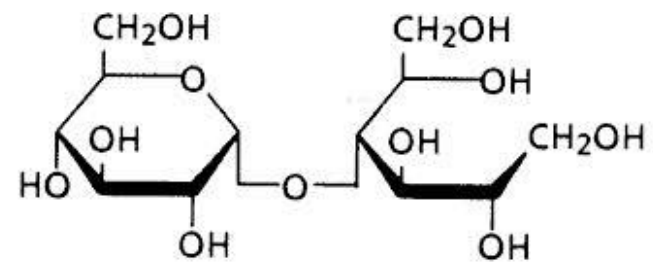

Fig. 3. Maltitol structure (source: www.cargillfoods.com/)

Methods

Tahini was produced by dehulling sunflower seeds, removing the hulls, roasting the kernels, and finally milling the roasted kernels to the desired granulometry. Using ratios from 60:40 to 40:60, tahini and nougat were mixed manually by the traditional method, obtaining the halva (Racolţa, 2008). By conventional technology the nougat is obtained either by beating concentrated sugar syrup together with citric acid and soapwort extract, or beating sugar and glucose syrup with soapwort extract. The new nougat obtained in this work was produced by replacing the sugar with isomalt and the glucose syrup with maltitol syrup, obtaining thus the dietetic nougat.

Starting from the classical technology of halva with nougat made of sugar and glucose syrup, with the factors: Boiling time 20 minutes and Beating time of the caramel mass with soapwort extract 15 minutes, the same ratios have been used for the dietetic nougat production and the following factors were varied:

Factor $A=$ Boiling time, with graduations:

$a_{1}=15$ min; $a_{2}=20 \mathrm{~min}$;

Factor $B=$ Beating time, with graduations:

$b_{1}=12 \mathrm{~min} ; b_{2}=18 \mathrm{~min}$;

From factors and graduations combinations a bi-factorial experiment design has been resulted with $2 \times 2=4$ variants. Working variants are presented in Tab. 1. Moreover, an additional variant 5, using same parameters as classical technology, have been produced as control. For each sample the dry matter has been determined by refractometric or oven method.

Each variant of nougat produced $(\mathrm{V} 1 \rightarrow \mathrm{V} 5)$ has been kneaded with a constant ratio of tahini (obtained by the conventional technology), resulting thus the corresponding sunflower dietetic halva prototypes $(\mathrm{P} 1 \rightarrow \mathrm{P} 5)$. 
Tab. 1

Working variants with experimental factors and their studied graduations

\begin{tabular}{|c|c|c|}
\hline Variant & $\begin{array}{c}\text { Factor A - Boiling time } \\
{[\mathrm{min}]}\end{array}$ & $\begin{array}{c}\text { Factor B - Beating time } \\
{[\mathrm{min}]}\end{array}$ \\
\hline V1: $\mathrm{a}_{1} \mathrm{~b}_{1}$ & 15 & 12 \\
\hline V2: $\mathrm{a}_{1} \mathrm{~b}_{2}$ & 15 & 18 \\
\hline V3: $\mathrm{a}_{2} \mathrm{~b}_{1}$ & 25 & 12 \\
\hline V4: $\mathrm{a}_{2} \mathrm{~b}_{2}$ & 25 & 18 \\
\hline
\end{tabular}

\section{RESULTS AND DISCUSSIONS}

The main outcome of the researches done was to propose a new technological process of the dietetic versions of halva and nougat. The technological operations are schematically presented in Fig. 4.

All dietetic halva samples produced were characterized from a sensorial point of view (Tab. 2), sample P4 showing the most pleasant appearance, color and texture.

Tab. 2

Sensorial properties of dietetic halva prototypes

\begin{tabular}{|c|c|c|c|}
\hline $\begin{array}{l}\text { Dietetic } \\
\text { halva } \\
\text { prototype }\end{array}$ & Appearance & Color & Texture \\
\hline P1 & $\begin{array}{ll}> & \text { unctuous mass } \\
> & \text { glossy surface } \\
> & \text { slightly stickiness } \\
> & \text { homogeneous mass }\end{array}$ & $\begin{array}{l}\text { slightly dark - caused by the lusterless } \\
\text { white colors of the nougat }\end{array}$ & $>$ soft rubberized \\
\hline P2 & $\begin{array}{ll}> & \text { unctuous mass } \\
> & \text { glossy surface } \\
> & \text { slightly stickiness } \\
> & \text { homogeneous mass }\end{array}$ & $\begin{array}{l}\text { pleasant color - nougat well beated } \\
\text { with a bright white color }\end{array}$ & $>$ soft rubberized \\
\hline $\mathbf{P 3}$ & $\begin{array}{ll}> & \text { regular shape, dried } \\
> & \text { not sticky } \\
> & \text { easily slicing } \\
> & \text { homogeneous mass }\end{array}$ & $\begin{array}{l}\text { slightly dark - caused by the lusterless } \\
\text { white colors of the nougat }\end{array}$ & $\begin{array}{ll}> & \text { without crumble } \\
& \text { when cut } \\
& \text { not rubberized } \\
& \text { slightly soft } \\
\end{array}$ \\
\hline P4 & $\begin{array}{ll}> & \text { regular shape, dried } \\
> & \text { not sticky } \\
> & \text { easily slicing } \\
> & \text { homogeneous mass }\end{array}$ & $\begin{array}{l}\text { pleasant color - nougat well beated } \\
\text { with a bright white color }\end{array}$ & $\begin{array}{l}>\quad \text { without crumble } \\
\text { when cut } \\
>\quad \text { not rubberized } \\
>\quad \text { slightly soft }\end{array}$ \\
\hline P5 & $\begin{array}{ll}> & \text { unctuous mass } \\
> & \text { slightly stickiness } \\
> & \text { homogeneous mass }\end{array}$ & $>$ acceptable color & $\begin{array}{l}>\text { slightly rubberized } \\
>\text { slightly soft }\end{array}$ \\
\hline
\end{tabular}




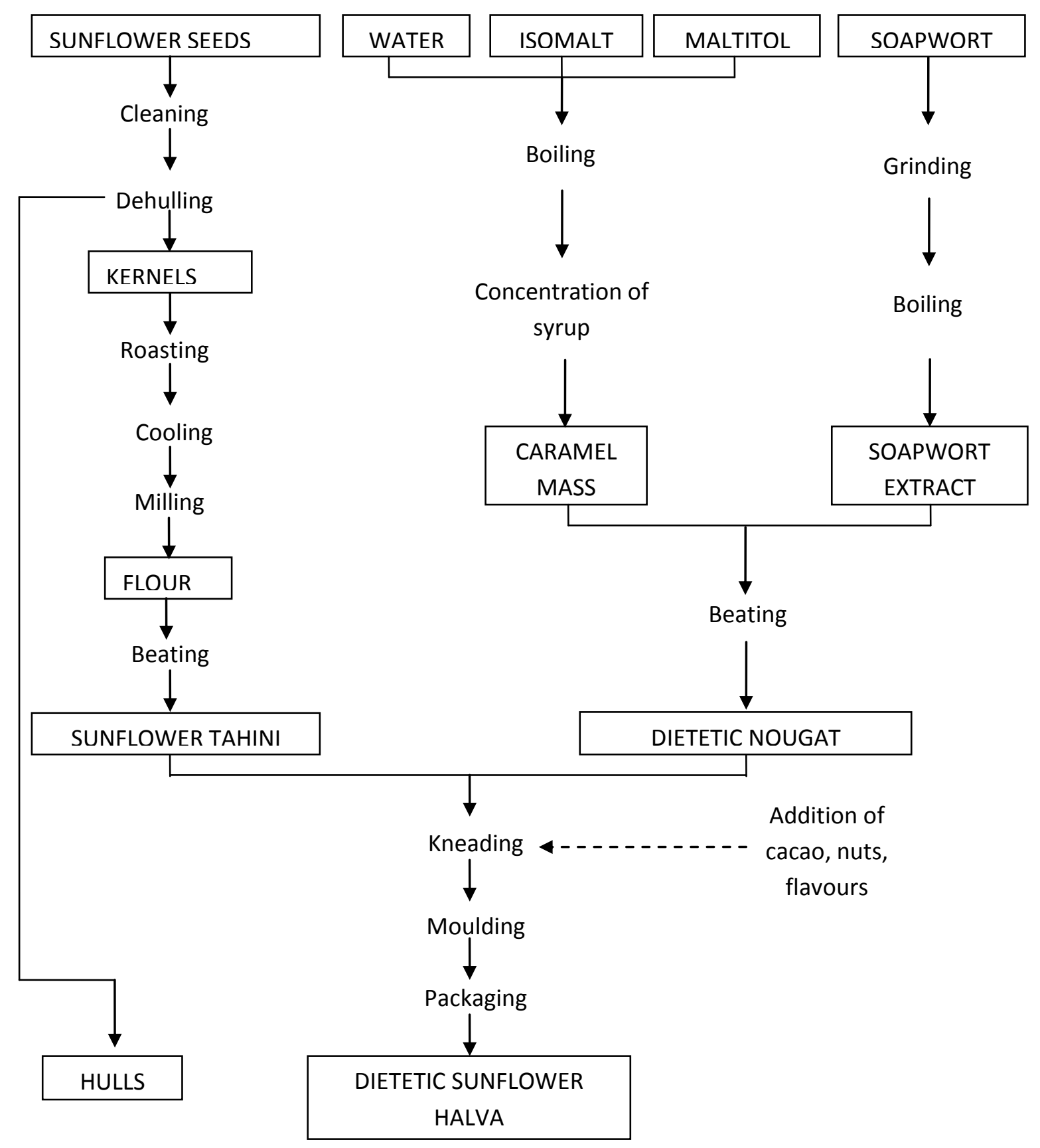

Fig. 4. Technological scheme of dietetic sunflower halva

For the chosen variant, the isomalt is dissolved in water, boiled to a concentration of 80 ${ }^{\circ}$ Brix, then the maltitol syrup is added and the boiling is continued to a concentration of $94^{\circ}$ Brix. Afterwards, the soapwort extract is added and the composition beated 18 minutes to ensure a proper air bubbles intake and density decrease to less than $1.1 \mathrm{~kg} / \mathrm{dm}^{3}$, obtaining those the dietetic nougat. The boiling operation takes place in double jackets caldrons, with a steam pressure of 4-5 bars. 
The dietetic nougat those obtained is kneaded with the tahini obtained by classical technology resulting in a new product, dietetic halva. The composition used or $100 \mathrm{~kg}$ of dietetic halva, for a ratio of 60:40 (tahini : nougat) is: $135 \mathrm{~kg}$ sunflower seeds, $21 \mathrm{~kg}$ isomalt, $21 \mathrm{~kg}$ maltitol syrup, $0.35 \mathrm{~kg}$ soapwort extract, $0.01 \mathrm{~kg}$ flavors (rum, vanilla, pistachio, almonds).

A new trend on halva production was established by developing a dietetic halva and nougat. The problem which is solved by the current work is to assure a proper technology in order to obtain a dietetic halva similar in taste and texture with the conventional one. The dietetic halva is intended for people with diabetes as well as for those which aim a health-oriented lifestyle.

\section{CONCLUSION}

To create an alternative for high caloric halva products (containing sucrose and glucose), it was developed a method to obtain dietetic halvas with no added sugar. The new products obtained have low energy and do not raise blood glucose and insulin levels. From a sensorial point of view the new product obtained is very similar with the conventional halva. Because it has no sugar, dietetic halva is an ideal product for consumers who will adopt healthier eating patterns, as long as halva still taste good and as long as they can still occasionally enjoy it without elevating blood glucose and insulin levels.

\section{REFERENCES}

1. Eissa, A. H. and A. Zohair (2006). Quality and safety of halawa modified with mushroom. J. Sci. Food Agric, 86:2551-2559.

2. Livesey G. (2003). Health potential of polyols as sugar replacers, with emphasis on low glycaemic properties. Nutrition Research Reviews 16: 163-191.

3. McNutt K. and A. Sentko (2003). Isomalt - IUFOST Report. International Union of Food Science and Technology, Elsevier Science Ltd.

4. Mureşan V., S. Muste, E. Racolta, C.A. Semeniuc, S. Man, A. Birou, C. Chircu (2010). Determination of Peroxide Value in Sunflower Halva using a Spectrophotometric Method. Bulletin UASVM Agriculture 67(2): 334-339.

5. Racolța, E. (2008). Tehnologia amidonului şi a produselor zaharoase. Editura Risoprint, ClujNapoca.

6. Eurostat (2011). Newsrelease, European Health Interview Survey, Between $8 \%$ and $25 \%$ of adults are obese across Member States. available at http://ec.europa.eu/eurostat (11.09.2013).

7. OECD (2012), Health at a Glance: Europe 2012. OECD Publishing http://dx.doi.org/10.1787/9789264183896-en.

8. $* * *$ http://www.cargillfoods.com/emea/en/products/sweeteners/polyols/maltidexmaltitol/functional/index.jsp (12.09.2013). 